\title{
Resultaten van training en begeleiding van student- docenten in het klinisch lijnonderwijs
}

\author{
A.J. Gercama, D. Tieleman, A. Retel Helmrich, J.F. Bastiaans
}

\section{Samenvatting}

Inleiding: Een belangrijk deel van het klinisch lijnonderwijs van de Faculteit Geneeskunde van de Vrije Universiteit Amsterdam wordt gegeven in studentgeleide probleemgestuurde onderwijsgroepen. Voor de student-begeleiders van deze groepen, de peergroepbegeleiders, is een trainings- en begeleidingstraject ontwikkeld.

Doel: Met het onderzoek werd vooral een antwoord gezocht op de vraag of de peergroepbegeleiders zich door het programma voldoende getraind en ondersteund voelden. Daarnaast is gekeken naar het functioneren van de peergroepbegeleiders en de tijdsinvestering die het programma vergt.

Methode: Door middel van schriftelijke enquêtes zijn de meningen van de peergroepbegeleiders en de studenten gepeild. Ook is het oordeel van studenten over de peergroepbegeleiders vergeleken met hun oordeel over staflid-docenten. De trainers van het begeleidingsprogramma hielden een tijdsregistratie bij.

Resultaten: De peergroepbegeleiders vinden dat training en begeleiding goed aansluiten bij hun verwachtingen en zij ervaren het traject als een duidelijke steun. Van de individuele begeleidingsmogelijkheden wordt weinig gebruik gemaakt. Studenten en peergroepbegeleiders zijn tevreden over het functioneren van de groep. Uit de vergelijking tussen studenten en stafleden als begeleiders bleek dat de studenten vooral beter scoren ten aanzien van persoonlijk functioneren en het stimuleren van het groepsproces. De totale tijdsinvestering komt op 0.1 fte op jaarbasis.

Beschouwing: De ervaringen met het begeleidingsprogramma en de oordelen over het functioneren van de groep zijn over het algemeen positief. Belangrijk is ook dat de studenten tevreden zijn over de begeleiding door peers en dat de tijdsbelasting voor docenten beperkt is. Gercama AJ, Tieleman D, Retel Helmrich A, Bastiaans JF. Resultaten van training en begeleiding van student-docenten in het klinisch lijnonderwijs. Tijdschrift voor Medisch Onderwijs 2001;20(3): 114-123.)

\section{Inleiding}

Sinds 1990 wordt aan de Faculteit Geneeskunde van de Vrije Universiteit (VU) in het tweede tot en met het vierde studiejaar, naast blokonderwijs, klinisch lijnonderwijs (KLO) gegeven. Dit onderwijs is aanvankelijk samen met de Universiteit van Amsterdam (UvA) ontwikkeld met als doel het oefenen van klinisch redeneren met behulp van casuïstiek. In het klinisch lijnonderwijs, ingevoerd in verschillende faculteiten, speelt de student als docent een belangrijke rol. ${ }^{1}$ Ook in het KLO aan de VU is er sprake van studentgeleid onderwijs of 'peer teaching'.

In de literatuur worden specifieke voordelen genoemd van de inzet van studenten in plaats van klinische docenten als begeleider bij het groepsgewijs oefenen van klinisch redeneren. Bij het oefenen van klinisch redeneren wordt veel belang gehecht aan het actief uitbreiden en verdiepen ('elaboreren') van kennis. ${ }^{2} 3$ 
Studenten begeven zich daarbij op onzeker terrein en zijn bang voor onjuiste of incomplete informatie. Student-begeleiders kennen deze situatie uit eigen ervaring en hebben dan ook in vergelijking met staf-begeleiders minder moeite om terughoudend te zijn ten aanzien van inhoudelijk ingrijpen. Studentgeleide groepen discussiëren meer met elkaar en richten zich meer op de toets dan groepen die door stafleden worden begeleid. ${ }^{4}$ Ook zijn student-begeleiders meer gericht op het groepsproces en de evaluatie ervan. ${ }^{4}$ Sobral constateerde dat na de inzet van student-begeleiders het onderwijs attractiever werd voor studenten en aan betekenis won. ${ }^{5}$

Studentgeleid onderwijs kan zeer productief zijn, wanneer voor een goede inbedding in het onderwijs wordt gezorgd. ${ }^{6}$ 7 Belangrijk zijn bijvoorbeeld de toetsing en de kwaliteit van het onderwijsmateriaal. ${ }^{8}$ Daarnaast is aandacht voor de student-begeleiders zelf van belang. Juist door de gemakkelijke identificatie met medestudenten ervaren zij problemen bij het uitvoeren van hun docentenrol. Zo wordt bijvoorbeeld van hen verwacht dat zij het gedrag van hun medestudenten zo beïnvloeden dat deze zich conformeren aan de KLO-werkwijze ten aanzien van klinisch redeneren.

Het KLO aan de VU wordt gegeven in het tweede, derde en vierde studiejaar. Afhankelijk van het studiejaar komen 'peergroepen' van veertien tot zestien studenten 13 tot 24 keer bijeen voor casusbesprekingen onder leiding van een vaste student-begeleider, de peergroepbegeleider. De tweede- en derdejaarsstudenten worden begeleid door een ouderejaarsstudent en de vierdejaarsstudenten door jaargenoten. Daarnaast nemen de groepen in dezelfde samenstelling deel aan zes tot acht werkgroepbijeenkomsten, die begeleid worden door een klinisch docent, de werkgroepbegeleider. Taken van de peergroepbegeleider zijn vierledig: het geven van instructie in de werkwijze, het geven van feedback op het groepsfunctioneren, het in overleg met de groep aanpakken van knelpunten in het groepsfunctioneren en het zo nodig bieden van inhoudelijke ondersteuning aan de hand van een docenteninstructie.

Voor een goede uitvoering van deze taken is een training van student-begeleiders gewenst. De ervaring met de aan de VU ontwikkelde training vormt de basis van dit artikel. Eerst wordt het trainingsen begeleidingstraject voor de studentbegeleiders beschreven en vervolgens worden de resultaten van een evaluatie van dit traject gepresenteerd.

\section{Training en begeleiding van de student-begeleiders}

Voor de peergroepbegeleiders is een trainings- en begeleidingstraject ontwikkeld. Dit bestaat uit een opstartbijeenkomst, een evaluatiebijeenkomst, een voorziening voor onderlinge consultatie en persoonlijke begeleiding, en een slotevaluatie. $^{9}$

\section{Trainingsbijeenkomst Opstarten van de peergroep}

Tijdens deze per studiejaar georganiseerde bijeenkomst wordt allereerst aandacht besteed aan het met elkaar kennismaken en het uitwisselen en verhelderen van verwachtingen ten aanzien van de training. Vervolgens wordt een op het betreffende studiejaar toegespitste training in het opstarten van een peergroep gegeven. In het tweede studiejaar gaat het vooral om het inoefenen van de methode en het regelmatig evalueren van de voortgang. In het derde studiejaar gaat het om het gebruik maken van en voortbouwen op de ervaringen van studenten in het jaar ervoor. In het vierde studiejaar draait het 
om het bespreken en oefenen van het geven van begeleiding terwijl men tevens groepslid is.

Als werkvorm wordt het rollenspel gehanteerd. De deelnemers spelen daarin de rol van een groep studenten uit het betreffende studiejaar en - beurtelings - de rol van begeleider. Tijdens de training wordt zoveel mogelijk teruggegrepen op de specifieke verwachtingen van de deelnemers.

De trainingssessies en de evaluatiebijeenkomsten worden geleid door twee stafleden. Een van hen treedt als hoofdtrainer op, de ander functioneert als co-trainer. De hoofdtrainer leidt het rollenspel in, stimuleert de deelnemers tot het geven van feedback en spitst deze toe op het functioneren van de begeleider bij het opstarten van de peergroep. De co-trainer bewaakt de voortgang van het programma, faciliteert de inbreng van de groepsleden en zorgt voor verslaglegging.

\section{Evaluatiebijeenkomst van de opstartfase}

$\mathrm{Na}$ vier tot vijf peergroepbijeenkomsten vullen de peergroepbegeleiders een enquête in over het functioneren van hun groep. De resultaten van deze enquête worden besproken op de evaluatiebijeenkomst, onder leiding van dezelfde trainers die de opstartbijeenkomst begeleiden. Tijdens de evaluatiebijeenkomst komen met name de knelpunten in het functioneren van groepen aan de orde. Deze worden besproken waarbij expliciet aandacht wordt besteed aan de vraag hoe men ze zou kunnen aanpakken. Indien gewenst, wordt een bepaalde aanpak in de groep geoefend als rollenspel.

\section{Onderlinge consultatie en persoonlijke begeleiding}

Tijdens het studiejaar kunnen peergroepbegeleiders op elkaar terugvallen voor steun en advies. Voor zover men onzeker is over de eigen rol als begeleider wordt gewezen op de mogelijkheid van intervisie. Daarnaast kunnen peergroepbegeleiders een beroep doen op persoonlijke begeleiding door de trainers. Deze mogelijkheid wordt expliciet aangeboden aan begeleiders die in de opstartfase problemen hebben ervaren met hun groep.

\section{Slotevaluatie}

$\mathrm{Na}$ afloop van het jaarprogramma komen de peergroepbegeleiders nog een keer bij elkaar. Op deze evaluatiebijeenkomst komt aan de orde hoe het verder met de groep is gegaan en wordt teruggeblikt op het trainings- en begeleidingtraject: In hoeverre is men in staat geweest voorkomende problemen aan te pakken en welke functie hebben training en begeleiding daarbij vervuld?

\section{Probleemstelling}

In het cursusjaar 1998/1999 heeft de begeleiding voor het eerst in deze vorm gefunctioneerd. In ons onderzoek waren wij in de eerste plaats geïnteresseerd of de peergroepbegeleiders zich door dit traject voldoende getraind en ondersteund achtten voor hun docentrol. Daarnaast wilden wij graag informatie over het effect ervan op hun functioneren als begeleider. Ten slotte waren wij geïnteresseerd in de docentbelasting van het programma. Dit leidde tot de volgende onderzoeksvragen: 1. Heeft het trainings- en begeleidingstraject de peergroepbegeleiders ondersteund in hun functioneren?

Welke verwachtingen hebben peergroepbegeleiders ten aanzien van de training en in hoeverre is hieraan voldaan? Hebben de peergroepbegeleiders daadwerkelijk gebruik gemaakt van de mogelijkheden tot begeleiding en in hoeverre hebben zij zich hierdoor ondersteund gevoeld?

2. Hoe hebben de peergroepbegeleiders gefunctioneerd?

Zijn zij in staat de peergroepen goed op te starten? Hoe beoordelen de studenten het 
functioneren van de peergroepbegeleiders? In hoeverre verschilt deze beoordeling van die over het functioneren van de werkgroepbegeleiders? Zijn peergroepbegeleiders in staat slecht functionerende groepen vroegtijdig te signaleren?

3. Welke tijdsinvestering vergt een dergelijk traject van docenten?

\section{Methoden}

\section{Ad 1. Heeft het trainings- en begelei- dingstraject de peergroepbegeleiders on- dersteund in hun functioneren?}

De verwachtingen van de deelnemers werden geïnventariseerd met behulp van een korte schriftelijke enquête direct voorafgaand aan de eerste trainingsbijeenkomst. Deze verwachtingen konden de peergroepbegeleiders ook inbrengen in een 'rondje', waarmee de bijeenkomst startte. Na afloop van de bijeenkomst gaven de deelnemers hun waardering voor de training aan in een korte enquête. Beide enquêtes bestonden uit vragen of uitspraken met vijf antwoordmogelijkheden op een Likertschaal van 1: volledig oneens tot 5: volledig eens. Daarnaast werd men via een open vraag uitgenodigd aanvullingen te geven.

Bij de eindevaluatie vulden de deelnemers eveneens een enquête in. Deze bestond uit twee gedeelten. In het eerste deel werd gevraagd hoe men het trainingsen begeleidingsaanbod had gewaardeerd en van welke aangeboden mogelijkheden men daadwerkelijk gebruik had gemaakt. In het tweede deel werd geïnformeerd naar het groepsfunctioneren. Ook deze enquête bestond voor een belangrijk deel uit vragen of uitspraken te scoren op een vijfpuntsLikertschaal. Het gebruik van begeleiding of consultatie werd geïnventariseerd met ja/nee-vragen met de mogelijkheid het antwoord toe te lichten. Verder werd gevraagd een rapportcijfer te geven voor het groepsfunctioneren. Van alle bijeenkomsten en de persoonlijke begeleidingsgesprekken werd een verslag gemaakt.

\section{Ad 2. Hoe hebben de peergroepbegelei- ders gefunctioneerd?}

Gezien de opzet van het onderzoek kon deze vraag slechts indirect worden beantwoord. In de eerste plaats vulden de peergroepbegeleiders een enquête in over het functioneren van de groepen ná de opstartfase. Meent de begeleider zelf dat het gelukt is de groep goed aan de gang te krijgen? De enquête bestond uit vragen of uitspraken met een vijfpunts-Likertschaal met de mogelijkheid het antwoord toe te lichten, en de vraag om een rapportcijfer te geven voor het groepsfunctioneren. Om een indruk te krijgen van de validiteit van het oordeel van de peergroepbegeleiders is aan de studenten een vergelijkbare enquête voorgelegd.

Daarnaast werden de studenten aan het eind van het studiejaar geënquêteerd over het functioneren van hun peergroepbegeleider. Ter vergelijking werd eveneens gevraagd naar hun oordeel over de werkgroepbegeleider. De significantie van eventuele verschillen tussen de beoordeling van peer- en werkgroepbegeleiders werd nagegaan met de rang-tekentoets volgens Wilcoxon. In deze enquête waren ook twee vragen opgenomen over het functioneren van de KLO-groep, respectievelijk als peeren als werkgroep. De antwoorden op deze vragen werden vergeleken met het oordeel van de peergroepbegeleiders van deze groepen na de opstartfase. Zo was het mogelijk een indruk te krijgen van de 'voorspellende waarde' van het oordeel van de peergroepbegeleiders ten aanzien van het signaleren van minder goed functionerende groepen. 
Ad 3. Welke tijdsinvestering vergt een dergelijk traject van de docenten?

In tegenstelling tot docenten dienen studenten ieder jaar opnieuw te worden getraind. De tijdsinvestering van de staf in het trainings- en begeleidingsprogramma is dan ook een factor van betekenis bij de afweging of men al dan niet studenten als begeleiders zal aanstellen. Om de tijdsinvestering te meten hielden beide docenten een tijdregistratie bij.

\section{Resultaten}

Heeft het trainings- en begeleidingstraject de peergroepbegeleiders ondersteund in hun functioneren?

In tabel 1 zijn de enquêteresultaten weergegeven. Men verwacht tijdens de training te leren over de werkwijze en over hoe problemen in de groep aan te kaarten en aan te pakken. Een tiental deelnemers formuleert specifieke verwachtingen. $\mathrm{Er}$ is vooral behoefte aan een nauwkeurige omschrijving van wat er van ze wordt verwacht en handige tips om een groep op gang te helpen of het klinisch denken te stimuleren. Na de training is men over het algemeen van mening dat deze aan de verwachtingen heeft voldaan en dat men voldoende is toegerust voor de opstartfase. Wanneer na afloop van het studiejaar wordt gevraagd wat men vindt van de gegeven training en begeleiding, acht men zich ook achteraf voldoende toegerust en is men positief over de geboden mogelijkheden. Over het nut van de evaluatiebijeenkomst en de bruikbaarheid van de gedane suggesties is men neutraal tot licht positief.

Wat betreft het gebruik van de aangeboden mogelijkheden blijken peergroepbegeleiders vooral gebruik te maken van onderlinge consultatie. Het spreekuur wordt weinig bezocht. Wel is er telefonisch contact. Intervisie vindt niet plaats (in tegenstelling tot de jaren ervoor, toen intervisie regulier werd aangeboden). In vier gevallen is contact opgenomen met de werkgroepbegeleider van de betreffende groep; in vijf gevallen is er sprake van persoonlijke begeleiding. Dit betreft een begeleider van een tweedejaarsgroep en vier begeleiders van vierdejaarsgroepen.

Van de vier peergroepbegeleiders van KLO4 die persoonlijk begeleid zijn, hadden twee een - naar het oordeel van de begeleider - slecht functionerende groep getroffen. Bij beiden bestond de begeleiding uit het voeren van een probleemverhelderend gesprek, een gesprek gericht op de aanpak van de problemen en het maken van follow-upafspraken. In één geval zijn de problemen in aanwezigheid van de gehele betreffende peergroep doorgesproken. Bij de eindevaluatie gaven beiden aan dat zij door de begeleiding weer de zin waren gaan inzien van hun taak en er ook weer plezier in hadden gekregen; anders had men zeker "het bijltje erbij neergegooid". In een derde geval was er sprake van een verschil in werkwijze met de meer directief optredende werkgroepbegeleider van de betreffende groep. Na probleemverheldering en bemiddeling door de onderwijscoördinator van de betreffende klinische afdeling vond een gesprek plaats met beide begeleiders. In dit gesprek was het mogelijk feedback uit te wisselen en te bespreken hoe men verder als begeleiders zou samenwerken. Zowel de peer- als de werkgroepbegeleider gaven achteraf aan dat na het gesprek de lucht geklaard was. De vierde begeleider uit KLO4 consulteerde al in de opstartfase, toen de groep een duidelijk ander, meer op de inhoud gericht, beeld van de begeleidersfunctie bleek te hebben dan de begeleider zelf. $\mathrm{Na}$ een gesprek over een goede aanpak van dit probleem, is zij met de groep verder gegaan. In een follow-upcontact gaf zij aan dat zij het probleem goed met de 
Tabel 1. Resultaat van de enquêtes over het programma Ondersteuning peergroepbegeleiders $K L O(N=46)$. De enquêtes zijn afgenomen voor en na de training en aan het eind van het studiejaar. Bij de vragen die beantwoord werden op een Likert-schaal $(1=$ in het geheel niet/zeer ontevreden/geheel oneens/zeer onvoldoende et cetera tot $5=$ volledig/zeer tevreden/geheel eens/ruim voldoende) zijn gemiddelde (gem.), standaarddeviatie (sd.) en het aantal antwoorden ( $N$ ) gegeven. Bij de ja/nee-vragen is het aantal keren vermeld dat de betreffende antwoorden zijn gegeven.

Gem.

- Voldeed deze trainingsmiddag aan uw verwachtingen?

Waardering aan het eind van het studiejaar

- Was u tevreden met de opzet van de trainingsbijeenkomst peergroepbegeleider te beginnen?

sd.
40

40

\section{4}

0.7

38

3.2

0.9

38

3.1

0.8

38

- Wat vind u van de geboden mogelijkheden voor ondersteuning/ begeleiding?

Mate waarin gebruik is gemaakt van begeleidingsmogelijkheden

- Heeft u het spreekuur bezocht?

- Heeft u telefonisch contact gehad?

- Heeft u contact gehad met collega-peergroepbegeleiders?

- Heeft u gebruik gemaakt van de mogelijkheid tot intervisie?

- Heeft u contact gehad met de werkgroepbegeleider van uw groep?

- Bent u persoonlijk begeleid? 
groep had kunnen uitpraten, zij het dat men weinig ruimte liet voor evaluatie van het groepsfunctioneren.

In de KLO2-groep vond één begeleidingsgesprek plaats. Aanleiding ertoe vormde het gegeven dat een deel van de groep zich in de opstartfase autonoom opstelde en zich van evaluaties niets leek aan te trekken. In een follow-upcontact gaf de begeleider aan dat het probleem zich inmiddels niet meer voordeed.

\section{Hoe hebben de peergroepbegeleiders gefunctioneerd?}

Het oordeel van de peergroepbegeleiders en de studenten over het groepsfunctioneren wordt weergegeven in tabel 2. De beoordeling door de peergroepbegeleiders komt goed overeen met die van de studenten. Wat opvalt, is de beperkte tijd die studenten uittrekken voor hun voorbereiding. Zij zijn behoorlijk tevreden over het functioneren van de peergroepbegeleider.

De resultaten van de enquête naar het oordeel van de studenten over het functioneren van de peergroepbegeleiders en de werkgroepbegeleiders zijn weergegeven in tabel 3. De studenten zijn in alle opzichten tamelijk tot zeer tevreden over de peergroepbegeleiders. De groepen zijn goed begeleid, voldoende geëvalueerd, de peergroepbegeleiders waren minder dan

Tabel 2. Enquête afgenomen na de opstartfase over het functioneren van de groep en de peergroepbegeleiders. De peergroepbegeleiders $(N=46)$ en de studenten $(N=620)$ beantwoordden de vragen op een vijfpuntsschaal ( $1=$ nooit, niemand, niet duidelijk, niet effectief, zeer ontevreden en $5=$ altijd, iedereen, heel duidelijk, zeer effectief, zeer tevreden). Weergegeven zijn het gemiddelde (gem.) en de standaarddeviatie (sd.).

\begin{tabular}{|c|c|c|c|c|c|c|}
\hline \multirow[b]{2}{*}{ Vragen } & \multicolumn{3}{|c|}{ Peergroepbegeleiders } & \multicolumn{3}{|c|}{ Studenten } \\
\hline & gem. & sd. & $\mathrm{N}$ & gem. & sd. & $\mathrm{N}$ \\
\hline \multicolumn{7}{|l|}{ - Is er tijdens de peergroepbijeenkomsten taakgericht } \\
\hline gewerkt en weinig tijd verspild aan onbelangrijke zaken? & 3.7 & 0.6 & 40 & 3.4 & 0.8 & 551 \\
\hline - Kreeg iedereen in de groep de kans iets bij te dragen & & & & & & \\
\hline aan de discussies? & 4.0 & 0.7 & 40 & 4.4 & 0.7 & 554 \\
\hline \multicolumn{7}{|l|}{ - Is in de groep steeds duidelijk onderscheid gemaakt } \\
\hline tussen een brainstormfase en een discussiefase? & 3.0 & 0.8 & 40 & 3.0 & 0.9 & 552 \\
\hline - Werden in de groep leerpunten/conclusies geformuleerd? & 2.9 & 1.1 & 40 & 2.9 & 0.9 & 552 \\
\hline $\begin{array}{l}\text { - Werd per bijeenkomst aandacht besteed aan evaluatie } \\
\text { van de werkwijze? }\end{array}$ & 3.1 & 1.0 & 40 & 3.3 & 0.9 & 553 \\
\hline \multicolumn{7}{|l|}{ - Werd per bijeenkomst aandacht besteed aan evaluatie } \\
\hline van het groepsproces? & 3.0 & 1.1 & 40 & 3.2 & 0.9 & 550 \\
\hline - Wat vond u van het effect van deze evaluaties? & 3.5 & 1.0 & 37 & 3.0 & 0.9 & 550 \\
\hline \multicolumn{7}{|l|}{ - Bent $u$ tevreden over de mate waarin de groep zich in het } \\
\hline algemeen voorbereidt? & 3.3 & 1.0 & 40 & 2.1 & 0.6 & 551 \\
\hline - Bent u tevreden over de wijze waarop de groep is gaan & & & & & & \\
\hline functioneren? & 4.0 & 0.7 & 40 & 3.7 & 0.8 & 553 \\
\hline - Bent u tevreden over de rol van de peergroepbegeleider? & & & & 4.0 & 0.7 & 553 \\
\hline - Welk rapportcijfer (1-10) geeft u de groep? & 7.4 & 1.0 & 40 & & & \\
\hline
\end{tabular}


Tabel 3. Oordeel studenten $(N=620)^{1}$ over de begeleiding door de peergroep-en de werkgroepbegeleiders. De vragen werden beantwoord op een vijfpuntsschaal $(1=$ zeer oneens/zeer slecht tot $5=$ zeer eens/zeer goed). Weergegeven zijn het gemiddelde (gem.) en de standaarddeviatie (sd.). Alle verschillen zijn significant $(p<0.05)$.

\begin{tabular}{|c|c|c|c|c|}
\hline \multirow[b]{2}{*}{ Vragen } & \multicolumn{2}{|c|}{ Peergroepbegeleider } & \multicolumn{2}{|c|}{ Werkgroepbegeleider } \\
\hline & gem. & sd. & gem. & sd. \\
\hline \multicolumn{5}{|l|}{ De peer- c.q. werkgroepbegeleider: } \\
\hline - was voldoende inhoudsdeskundig & 3.8 & 0.9 & 4.0 & 0.8 \\
\hline \multicolumn{5}{|l|}{ - heeft het gebruik van de KLO-werkwijze } \\
\hline voldoende gestimuleerd & 3.6 & 0.9 & 3.3 & 0.9 \\
\hline \multicolumn{5}{|l|}{ - zag er op toe dat de 'key features' voldoende } \\
\hline aan bod kwamen & 3.9 & 0.9 & 3.6 & 1.0 \\
\hline - hield zich afzijdig bij een goed verloop van de bijeenkomst & 4.1 & 0.8 & 3.7 & 1.1 \\
\hline - heeft steeds ingegrepen wanneer de groep afdwaalde & 3.9 & 0.9 & 3.7 & 1.0 \\
\hline - heeft met de groep voldoende geëvalueerd & 3.8 & 0.9 & 3.2 & 1.1 \\
\hline - stond zelf open voor kritiek uit de groep & 4.1 & 0.9 & 3.6 & 1.2 \\
\hline - was enthousiast & 4.1 & 1.1 & 3.4 & 1.4 \\
\hline - was afwezig (nul, 1, 2, 3, 4 of meer keer) & $4.3^{2}$ & 1.0 & 3.9 & 1.1 \\
\hline
\end{tabular}

1 In alle gevallen werd de vraag door 556 studenten beantwoord.

24 of meer keer afwezig $=1,3$ keer $=2,2$ keer $=3,1$ keer $=4$ en nul keer $=5$.

eenmaal afwezig, waren zeer enthousiast en hebben tamelijk goed toegezien op het gebruik van de KLO-werkwijze.

De peergroepbegeleiders scoren - behalve op inhoudsdeskundigheid - hoger dan de werkgroepbegeleiders. De verschillen ten opzichte van de werkgroepbegeleiders zijn vooral duidelijk ten aanzien van punten die met het persoonlijk functioneren en het stimuleren van het groepsproces te maken hebben (afzijdig blijven bij goed verloop, evalueren van de groep, open staan voor kritiek, enthousiasme). De gevonden verschillen zijn alle significant (Wilcoxon rang-tekentoets, tweezijdig getoetst, $\mathrm{p}<0.05$ ).

Het oordeel van de studenten over het groepsfunctioneren in werk- en peergroep is weergegeven in tabel 4 . In vier groepen (één in het tweede en drie in het vierde jaar) was de gemiddelde score voor het functioneren als peergroep lager dan 3.0 en daarmee duidelijk lager dan het gemiddelde over alle groepen. In alle vier gevallen heeft de betreffende peergroepbegeleider dit minder goede functioneren gesignaleerd in de opstartfase. In drie gevallen leidde dit tot persoonlijke begeleidingsgesprekken. Gezien het - onveranderd - kritische oordeel van twee van hen (en een lagere beoordeling van de derde) bij de eindevaluatie én het oordeel van de studenten hebben deze gesprekken niet geleid tot een duidelijke verbetering in het functioneren van deze groepen.

\section{Welke tijdsinvestering vergt een dergelijk traject van de docenten?}

Op basis van de urenregistratie van de docenten die betrokken waren bij het trainings- en begeleidingstraject (AG en DT) is de benodigde tijdsinvestering berekend. Het organiseren en uitvoeren van de trainings- en evaluatiebijeenkomsten nam 
Tabel 4. Beoordeling van het functioneren van de peergroepen door de studenten $(N=556)$. Weergegeven zijn de gemiddelde scores (gem.) en de standaarddeviaties (sd.) van de beoordeling op een vijfpuntsschaal ( $1=$ zeer oneens; $5=$ zeer eens) voor alle groepen $(N=46)$ en de slecht functionerende groepen (groepen met score $<3, N=4)$.

\begin{tabular}{llllll}
\hline & Alle groepen & \multicolumn{3}{c}{$\begin{array}{c}\text { Slecht } \\
\text { functionerende- } \\
\text { groepen }\end{array}$} \\
& gem. & sd. & & gem. & sd. \\
\hline - Ik ben over het algemeen genomen tevreden over de & & & & & \\
$\quad$ manier waarop onze groep als peergroep heeft gefunctioneerd. & 4.0 & 0.9 & & 2.7 & 0.2 \\
- Ik ben over het algemeen genomen tevreden over de manier & & & & & \\
$\quad$ waarop onze groep als werkgroep heeft gefunctioneerd. & 3.7 & 1.0 & 3.4 & 0.2 \\
- Rapportcijfer peergroepbegeleider na opstartfase & 7.4 & 1.0 & 6.7 & 0.7 \\
- Rapportcijfer peergroepbegeleider bij eindevaluatie & 7.5 & 0.7 & 6.5 & 0.5 \\
\hline
\end{tabular}

120 uur in beslag, het organiseren en uitvoeren van de persoonlijke en de spreekuurcontacten 30 uur. De sollicitatieprocedure kostte 60 uur, zodat de totale tijdsinvestering uitkomt op 210 uur (ruim $0.1 \mathrm{fte})$ op jaarbasis.

\section{Beschouwing en conclusies}

Ten aanzien van de eerste vraag kunnen de volgende conclusies worden getrokken. Het trainings- en begeleidingstraject sluit goed aan bij de verwachtingen van de deelnemers. De begeleiders voelen zich in het algemeen voldoende gesteund, terwijl zij in feite maar beperkt gebruik maken van de aangeboden mogelijkheden tot persoonlijke begeleiding. Onderlinge consultatie vindt veel plaats. Persoonlijke begeleiding kan afhaken van peergroepbegeleiders helpen voorkomen. Effect op het groepsfunctioneren kon echter niet aangetoond worden.

Wat betreft hun functioneren blijken peergroepbegeleiders in staat problematisch functioneren van groepen in een vroeg stadium te signaleren. Naar het oordeel van de studenten bij de eindevaluatie doen zij als begeleider zeker niet onder voor klinische docenten/werkgroepbegeleiders. Op een aantal punten die enerzijds met het stimuleren van het groepsproces (afzijdig blijven bij goed verloop, gericht zijn op evaluatie) en anderzijds met het persoonlijk functioneren (openstaan voor kritiek, keren afwezig zijn en enthousiasme voor de taak) te maken hebben, scoren zij beter dan stafdocenten.

De docentbelasting van het trainings- en begeleidingstraject laat zich becijferen op 210 uur (op jaarbasis). Dit betekent dat met een - in kwantitatieve zin - beperkte inspanning van de staf het facultaire medisch onderwijs aan de Vrije Universiteit jaarlijks wordt verrijkt met de inzet van een flink aantal enthousiaste studentdocenten.

\section{Literatuur}

1. Cate ThJ ten. Kleinschalig theoretisch klinisch lijnonderwijs. Ned Tijdschr Geneeskd 1994; (138): 1238-43.

2. Bastiaans JF, Huinink S, Ittersum FJ van, Sagasser MH. Rapport OKF-project: Klinisch probleemoplossen in de praktijk. Amsterdam: Vrije Universiteit; 1998.

3. Regehr J, Norman Y. Issues in cognitive psychology: Implications for professional education. Acad Med 1996;71:988-1001. 
4. Moust JHC. De effectieve tutor: meer dan alleen een vakinhoudelijk deskundige? Tijdschrift voor Hoger Onderwijs 1994;12:95-115.

5. Sobral DT. Peer tutoring and student outcomes in a problem-based course. Med Educ 1994;28:284-9.

6. Cate ThJ ten, Tromp Th, Cornwall MG. De student als docent. Aula 814. Utrecht: Het Spectrum; 1984.

7. Cate ThJ ten. Leren in groepen zonder docent [proefschrift]. Amsterdam: Universiteit van Amsterdam; 1986.

8. Bastiaans JF, Ittersum FJ van, Sagasser $\mathrm{MH}$, Gercama AJ, Haan M de. Zeven jaar klinisch lijnonderwijs aan de Vrije Universiteit; de problemen, de docententraining en het onderwijsmateriaal. Tijdschrift voor Medisch Onderwijs 2000;19:218-24.

9. Gercama AJ, Retel Helmrich A, Tieleman D. De student als rolmodel in het onderwijs: Training en begeleiding van begeleiders van studentgeleide onderwijsgroepen in het KLO. Amsterdam: Vrije Universiteit; 1999.
De auteurs:

A.J. Gercama, huisarts; universitair docent, Afdeling Huisartsgeneeskunde.

D. Tieleman, arts; destijds junior docent, Afdeling Huisartsgeneeskunde.

A. Retel Helmrich, onderwijskundige; Onderwijsbureau. J.F. Bastiaans, huisarts; universitair docent, Afdeling Huisartsgeneeskunde.

Allen zijn verbonden aan de Faculteit Geneeskunde, Vrije Universiteit Amsterdam.

Correspondentieadres:

A.J. Gercama, Afdeling HVSG, Faculteit Geneeskunde, Vrije Universiteit, Van der Boechorststraat 7, 1081 BT Amsterdam, tel: 020-4448245/40, fax: 020-4448388, e-mail:aj.gercama.gpnh@med.vu.nl.

\section{Summary}

Introduction: A significant part of the course in clinical problem solving at the medical school of the Free University, Amsterdam, the Netherlands, consists of a problem based small group programme facilitated by students, the so-called peer group facilitators. A training and coaching programme provided for the student facilitators has been evaluated.

Purpose: The main issue studied was whether the peer group facilitators consider themselves adequately prepared and supported by the programme. Other issues were the functioning of the peer group facilitators and the amount of time the trainers spent on the programme.

Methods: Various questionnaires were administered to peer group facilitators and students at different points in the programme. The trainers recorded the hours they spent on the programme.

Results: The programme meets the expectations of the peer group facilitators, who feel supported by it. Little use is made of individual coaching. Both peer group facilitators and students express satisfaction with the functioning of the groups. Students give higher scores to student facilitators compared with those for clinician facilitators on personal functioning and as facilitators of the group process. The programme requires 0.1 fte annually.

Discussion: The experiences with the programme and the perceptions regarding the functioning of the groups are generally positive. It is encouraging that students appreciate their peer teachers and that the training and coaching programme requires a limited amount of time from trainers. (Gercama AJ, Tieleman D, Retel Helmrich A, Bastiaans JF. Training and coaching students for small group peer teaching. Dutch Journal of Medical Education 2001;20(3): 114-123.) 